\title{
O PLANO NACIONAL DE EDUCAÇÃO E O INGRESSO DOS PROFISSIONAIS DO MAGISTÉRIO DA EDUCAÇÃO BÁSICA
}

\author{
Vera LÚCia AlVes de Brito*
}

\begin{abstract}
RESUMO: O objetivo do artigo é avaliar a Meta 18 do Plano Nacional de Educação (PNE), relativo a 2011-2020, investigando a situação atual dos ingressos temporários de professores em diversos estados brasileiros. A estratégia da referida Meta propõe que $90 \%$ dos profissionais do magistério em exercício na rede pública de educação básica estejam nomeados em cargos de provimento efetivo no prazo de dois anos após a promulgação do Plano Nacional de Educação 2011-2020. O trabalho enfoca a questão da valorização dos profissionais da educação na legislação e na literatura, abrangendo as políticas públicas propostas e sua efetiva implementação. Na questão específica sobre o ingresso por concurso público, nas redes públicas investigadas, a pesquisa apontou recorrentes contratações temporárias de docentes, o que indica possíveis limites para a implantação da referida estratégia.

Palavras-chave: Profissão docente. Plano Nacional de Educação. Valorização de professores.
\end{abstract}

\section{The National Education Plan and the employment of BASIC EDUCATION PROFESSIONALS}

\begin{abstract}
The main goal of this article is to evaluate the $18^{\text {th }}$ Goal of the National Education Plan (2011-2020) by investigating the current situation of teachers under temporary contracts in several states in Brazil. The strategy of the referred Goal considers that $90 \%$ of the Education professionals in the basic education public network will have to be nominated within two years after the promulgation of the National Education Plan 2011-2020. This article focuses on the issue of Education professionals' appreciation, both in the legislation and literature, questioning the public policies proposals and their effective implementation. Regarding the specific question related to the admission of teachers by public tender, the research pointed out recurrent acts of temporary employment of teachers which indicate possible limitations for the implementation of the referred strategy.
\end{abstract}

Key words: Teaching profession. National Education Plan. Teachers appreciation.

Faculdade de Educação da Universidade do Estado de Minas Gerais (UEMG). Belo Horizonte (MG) - Brasil.

Contato com a autora: <veraluciabrito@ig.com.br> 


\title{
Le Plan National d'Éducation et l'admission des
} PROFESSIONNELS DE L'ENSEIGNEMENT DE L'ÉDUCATION BASIQUE

\begin{abstract}
RÉSUMÉ: L'objectif de l'article est évaluer l'Objectif 18 du Plan National d'Éducation (PNE) concernant la période entre 2011 et 2020, en enquêtant la situation actuelle des admissions temporaires des enseignants dans de divers Etats brésiliens. La stratégie de cet Objectif propose que 90\% des professionnels de l'enseignement dans le réseau public d'éducation basique soit nommé dans un délai de deux ans après la promulgation du Plan National d'Éducation 2011-2020. Le travail met en question la valoration des professionnels de l'éducation dans la législation et dans la littérature, en interrogeant les politiques publiques des propositions et la mise en œuvre effective d'implementation. Dans la question spécifique sur l'admission par concours publics, dans l'enseignement public, la recherche a indiqué de récurrents contrats temporaires des enseignants ce qui indique de possibles limites pour l'implantation de cette stratégie.
\end{abstract}

Mots-clés: Métier d'enseignants. Plan National de l'Éducation. Valorisation des enseignants.

$\mathrm{A}$ educação brasileira vive, nesse momento, o acirramento da contradição entre a necessidade de uma educação de qualidade e a desvalorização profissional dos professores. Afirma-se a centralidade da atuação dos professores para o avanço da qualidade da educação. Contudo, as políticas públicas não têm alcançado o retorno esperado em relação ao desenvolvimento profissional, à valorização docente e à remuneração dos profissionais da educação. As propostas de institucionalização da carreira docente têm sido recorrentemente normatizadas, porém a efetividade das políticas públicas continua posta em questão.

Este artigo tem como objetivo analisar a contradição entre a valorização dos profissionais da educação presente na legislação educacional e a forma efetiva das condições de ingresso, das condições de trabalho e da carreira dos profissionais da educação. O artigo destaca a Meta 18 do Plano Nacional de Educação (1011-2020) como um problema fundamental da questão da valorização e do desenvolvimento profissional da categoria.

\section{A questão da valorização dos profissionais da educação}

Presente em diferentes momentos da educação brasileira, a questão da valorização dos profissionais da educação volta à agenda pública na década de 1980, com a redemocratização política.

$\mathrm{Na}$ Assembleia Nacional Constituinte, as discussões sobre a valorização dos profissionais da educação surgem como um eixo fundamental da educação de 
qualidade. A Constituição Federal de 1988 (CF/88) dispôs, no artigo 206, entre os princípios para o ensino: "a valorização dos/as profissionais da educação escolar, garantidos, na forma da lei, planos de carreira, com ingresso exclusivamente por concurso público de provas e títulos, aos das redes públicas" (Redação dada pela EC n. 53, de 2006).

A Lei de Diretrizes e Bases da Educação Nacional (LDBEN, Lei n. 9.394, de 20 de dezembro de 1996) apresentou de modo articulado os conceitos de valorização do profissional da educação, a garantia do padrão de qualidade e o "custo aluno".

O texto aprovado em 1996 reitera entre os princípios da educação nacional da Constituição Federal de 1988: "Art. 3o - a valorização do profissional da educação escolar" e "a garantia de padrão de qualidade".

A LDBEN, em sua formulação original, dispõe sobre a valorização dos profissionais da educação pública, assegurando "aperfeiçoamento profissional continuado, inclusive com licenciamento periódico remunerado para este fim"; e também "progressão funcional baseada na titulação ou habilitação, e na avaliação de desempenho" (BRASIL, 1996).

Em 2013 há alteração expressiva da LDBEN no item referente à formação e valorização dos profissionais da educação. A Lei n. 12.796, de 4 de abril de 2013, insere no artigo 62 os incisos $4^{\circ}, 5^{\circ}$ e $6^{\circ}$ :

$4^{\circ}$ A União, o Distrito Federal, os estados e os municípios adotarão mecanismos facilitadores de acesso e permanência em cursos de formação de docentes em nível superior para atuar na educação básica pública.

5ำ A União, o Distrito Federal, os estados e os municípios incentivarão a formação de profissionais do magistério para atuar na educação básica pública, mediante programa institucional de bolsa de iniciação à docência a estudantes matriculados em cursos de licenciatura, de graduação plena, nas instituições de educação superior.

6ํㅡㄴ Ministério da Educação poderá estabelecer nota mínima em exame nacional aplicado aos concluintes do ensino médio como pré-requisito para o ingresso em cursos de graduação para formação de docentes, ouvido o Conselho Nacional de Educação - CNE.

As inovações dessa Lei ainda suscitam alguns questionamentos para sua melhor compreensão, à medida que faltam algumas explicitações.

A Lei n. 12.796 inova, ao estabelecer no artigo 62-A: a criação de cursos de conteúdo técnico-pedagógico, em nível médio ou superior, incluindo habilitações tecnológicas. No Parágrafo único estabelece que "Garantir-se-á formação continuada para os profissionais a que se refere o caput, no local de trabalho ou em instituições de educação básica e superior, incluindo cursos de educação profissional, cursos superiores de graduação plena ou tecnológicos e de pós-graduação". 
O artigo 67 da LDBEN inclui a valorização dos profissionais da educação, assegurando planos de carreira, concurso público de provas e títulos, profissional, piso salarial profissional; aperfeiçoamento profissional continuado, com licenciamento ou remunerado; progressão funcional baseada na titulação ou habilitação, e na avaliação do desempenho; período reservado a estudos, planejamento e avaliação, incluído na carga de trabalho; condições adequadas de trabalho. A Lei n. 12.796/2013 insere o inciso 3: "A União prestará assistência técnica aos estados, ao Distrito Federal e aos municípios na elaboração de concursos públicos para provimento de cargos dos profissionais da educação".

A LDBEN, ao articular a valorização do profissional, garantia do padrão de qualidade, institui o conceito de "custo-aluno" articulado à ação supletiva da União e dos estados. A alteração do financiamento da educação não dispensa o conceito de custo-aluno. Reafirma também a ação supletiva da União e a valorização docente. A Lei n. 9.424/1996 regulamentou o Fundo de Manutenção e Desenvolvimento do Ensino Fundamental e de Valorização do Magistério (Fundef), instituído pela EC n. 14/1996, no âmbito de cada estado e do Distrito Federal. O Fundo foi composto por $15 \%$ dos impostos e contribuições: ICMS, FPE e FPM, IPI, recursos para compensação da Lei Complementar n. 87/96. A Lei explicita a distribuição dos recursos, a utilização de $60 \%$ para a remuneração do magistério e a exigência de planos de carreira.

Em um novo contexto político, com ampla participação da sociedade civil organizada, resultaram propostas de maior comprometimento da União no apoio financeiro à educação básica. Na EC n. 53/2006, que criou o Fundo de Manutenção e Desenvolvimento da Educação e de Valorização dos Profissionais da Educação Básica (Fundeb), foi mantida a lógica do Fundef e definido que o valor anual por aluno será a referência para a remuneração dos profissionais da educação. A abrangência do Fundeb foi ampliada para toda a educação básica e o percentual de subvinculação de receita foi aumentado, como também o número de impostos envolvidos.

A EC n. 53/2006 reafirma, uma vez mais, a valorização dos profissionais da educação pela implantação de planos de carreira e remuneração, de modo a assegurar: I - a remuneração condigna dos profissionais na educação básica da rede pública; II - integração entre o trabalho individual e a proposta pedagógica da escola; III - a melhoria da qualidade do ensino e da aprendizagem.

A mudança no financiamento e a expressa vinculação do financiamento ao pagamento de professores foram consideradas, naquele momento histórico, a solução ideal para a valorização docente. Corroborando esta expectativa, pesquisadores avaliaram que o aumento da arrecadação de recursos do Fundeb poderia ter sido suficiente para que todos os estados e municípios implantassem um piso salarial 
básico para os professores. No entanto, o governo federal não cumpriu o que estava determinado na legislação. Como afirma Abicalil (2008, p. 72):

\begin{abstract}
Nesse sentido, o Fundef avançou, garantindo um custo aluno médio básico dentro de cada estado, para o ensino fundamental, ao qual deveria corresponder um "salário médio". Porém, não se constituiu num mecanismo que assegurasse o piso salarial profissional nacional, referência para a estruturação das carreiras em cada estado e município [...]. Essa é uma das tarefas do Fundeb, compromisso programático do Governo Lula, configurado na Emenda Constitucional de número 53 (EC 53) [...].
\end{abstract}

Em 16 de julho de 2008, foi sancionada a Lei n. 11.738, instituindo o Piso Salarial Profissional Nacional (PSPN). Entretanto, o cálculo do valor deste piso não foi cumprido, o que gerou protestos do movimento sindical dos professores.

Em decorrência da autonomia federativa, o piso salarial nacional não foi, até o ano de 2013, implantado em todos os estados e municípios, pois alguns entes federados ainda não se consideram com condições de aplicá-lo. Isto aponta para a desigualdade na distribuição de recursos nos diversos estados e municípios. Embora as políticas educacionais para a educação básica tenham inovado no financiamento, estabelecendo fundos contábeis (Fundef e Fundeb), a desigualdade na distribuição de recursos nos diversos entes federados demonstra as inadequações das políticas públicas para corrigir as distorções financeiras entre municípios e estados.

\title{
As relações de trabalho no serviço público
}

Para analisar o ingresso na profissão docente, no Brasil, é importante investigar como as transformações do mundo do trabalho têm incidido tanto nas dimensões subjetivas da escolha da profissão, como na dimensão objetiva. No caso específico da pesquisa realizada, foram investigadas as relações de trabalho no serviço público que se referem a um modelo de relações de trabalho diferenciadas daquelas existentes na empresa privada.

Ao analisar os serviços públicos na França, do ponto de vista das relações jurídicas do trabalho, Alain Supiot (1995, p. 2) indaga sobre a diferença entre as relações de trabalho na empresa privada e no serviço público: “Já de saída, é de bom alvitre indagar-se que diferença é essa; ou, "em outras palavras, em que consiste o espírito de serviço público aplicado às relações de trabalho antes de se estudarem as razões de sua desestabilização e as reações por esta suscitadas".

Em síntese, Supiot propõe uma reflexão sobre a oposição entre o contrato e o estatuto, como um caminho para a pesquisa sobre o tema. Opõe o contrato nas empresas privadas, que permite que se faça do trabalho um objeto de negócio, e o 
estatuto do funcionário público, que, ao contrário, separa relações de trabalho e esfera comercial. Nesta perpectiva, há, pelo contrato, um consenso entre o assalariado que vende seu trabalho àquele que, no mercado de trabalho, lhe oferece mais por ele; a relação, nesse caso, é assimétrica porque um dos contratantes se coloca sob as ordens do outro. Há uma relação recíproca entre o empregado que se propõe a trabalhar subordinado ao empregador, tendo como contrapartida o salário. A duração deste contrato é aleatória. Nenhuma dessas características se encontra no estatuto do funcionário público, que implica outra relação com o poder, o dinheiro e o tempo de trabalho:

Quanto ao estatuto, as coisas são mais complexas: a relação com o poder não se reduz à relação entre o funcionário e a hierarquia, mas, sim, inclui o público, a cujo serviço ambos se encontram; e a ideia de moral profissional impregna tanto a relação com o público, como a relação com o superior hierárquico. (SUPIOT, op. cit., p. 3)

Desse modo, o funcionário público tem uma relação diferente com o usuário, porque este é "titular de direitos" e não apenas cliente, como na relação empresa/ cliente. Em consequência, todos os usuários do seviço público têm direito a serem tratados com igualdade e têm direito a um serviço de qualidade. A remuneração, portanto, não é a contrapartida direta da soma das prestações de serviço, não tendo como indexador financeiro o valor de mercado. Em sua relação com o superior hierárquico, o funcionário não se subordina a uma determinada pessoa, mas sim a uma organização e aos valores por ela encarnados. A dimensão coletiva do trabalho reveste-se de particular importância: a da colaboração de todos em prol de um objetivo comum: o serviço público a ser prestado pelo Estado.

A implantação do modelo burocrático de administração é recente no Brasil. Os princípios de uma administração baseada em critérios racionais-legais buscavam principalmente substituir uma administração patrimonialista, que proporcionava o aparecimento do clientelismo, nepotismo, empreguismo e, até mesmo, da corrupção, e combater essas práticas. Segundo Ferreira (1996, p. 8):

O modelo de administração pública burocrática surge com a preocupação de combater os excessos do modelo patrimonialista, caracterizado pela confusão entre o interesse público e o privado: o Estado, nessa visão, era quase que uma extensão da família real e tinha como atribuição fundamental administrar os bens da realeza.

Neste sentido a burocracia representaria um tipo de administração pública que se justificava na Europa, na época do Estado liberal, como um antídoto ao patrimonialismo.

Até 1930, segundo Ferreira (op. cit.), a administração pública brasileira era moldada pelo velho estilo patrimonial do favoritismo político e social, sem qualquer 
distinção entre o público e o privado. Nesse sentido, segundo Avellar (1983, p. 329), o Departamento Administrativo do Serviço tinha a função de pôr fim ao "caráter político do recrutamento do funcionalismo, partindo do imperativo técnico da neutralidade do serviço e do servidor público".

Contudo, não é uma tarefa fácil reestruturar a máquina administrativa, empreendendo princípios universalistas e democráticos. Isto explica por que sucessivos governos buscaram saídas jurídicas para driblar estes princípios. Tanto em nível federal, estadual ou municipal há dificuldade em organizar uma administração pública dentro dos critérios de neutralidade e de democratização do setor público. Esta dificuldade manifestou-se ora pela criação de sistemas de administração indireta, como fundações públicas, ora na prática de terceirização ou mesmo inserção de práticas jurídicas de burla dos princípios democráticos.

Diante destas considerações iniciais, como analisar o ingresso na carreira do magistério público sem a referência à condição do professor das escolas públicas como um servidor público? Contudo, é preciso responder primeiro à seguinte questão: Todos os professores públicos estão incluídos nas vantagens do estatuto dos servidores públicos?

O trabalho docente como elemento próprio do Estado remonta, segundo Nóvoa (1991), às transformações políticas e econômicas da Europa do século XIX, quando o professor se transforma gradativamente em funcionário do Estado, passando a obter garantias de estabilidade de emprego, progressão por tempo de serviço e não estar sujeito à exclusão pelas vicissitudes políticas locais. Esse processo de profissionalização do trabalho docente foi se tornando mais complexo, o que se expressaria na elaboração e promulgação de ordenamentos legais sobre a profissão.

\section{A pesquisa realizada}

O objetivo do trabalho é analisar a contradição entre a valorização dos profissionais da educação presente na legislação educacional e a forma efetiva das condições de ingresso, das condições de trabalho e da carreira dos profissionais da educação em alguns entes federativos brasileiros. O artigo destaca a Meta 18 do Plano Nacional de Educação 2011-2020 (em tramitação no Congresso Nacional) como um problema fundamental da questão da valorização e do desenvolvimento profissional da categoria.

A Meta 18.1, objeto desse artigo, insere-se na questão da valorização dos profissionais da educação que se desdobra em quatro metas (15 a 18) e em respectivas estratégias para sua implantação. Sintetizamos, a seguir, algumas dessas propostas. A Meta 15 propõe que todos os professores da educação básica possuam formação 
de nível superior, obtida em curso de licenciatura na área em que atuam. As estratégias propostas abrangem questões relativas ao incentivo à iniciação na docência, institucionalização da política nacional de formação e valorização dos profissionais da educação, reforma curricular dos cursos de licenciatura, programas de formação para professores em exercício. A Meta 16 propõe Formar $50 \%$ dos professores da educação básica em nível de pós-graduação. As estratégias visam assegurar a formação continuada, o sistema nacional de formação de professores, o livro didático, o portal eletrônico e licenças para qualificação.

A Meta 17 propõe aproximar o rendimento médio do profissional do magistério com mais de 11 anos de escolaridade do rendimento médio dos demais profissionais com escolaridade equivalente. As estratégias buscam, entre outras ações, instituir o Fórum para atualização do valor do piso salarial profissional, planos de carreira e jornada de trabalho em um único estabelecimento escolar.

A Meta 18 visa assegurar, no prazo de dois anos, planos de carreira para os profissionais do magistério em todos os sistemas de ensino. As estratégias propostas incluem: programa de acompanhamento do professor iniciante, prova nacional de admissão de docentes, censo dos funcionários e oferta de cursos técnicos para os mesmos, o provimento de cargos efetivos para as escolas indígenas, o repasse de transferências voluntárias para estado e municípios que tenham planos de carreira aprovados por lei.

A investigação apresentada nesse trabalho destacou a Meta 18 e a primeira estratégia para a análise de sua efetividade em alguns estados pesquisados. A Meta 18.1 propõe atingir, no quadro de profissionais do magistério, 90\% de servidores nomeados na educação básica.

É importante ressaltar que as metas inseridas no projeto do Plano Nacional de Educação também visam consolidar programas governamentais em execução. Um dos exemplos a ser citado é o Exame Nacional de Ingresso na Carreira Docente. Após várias tentativas anteriores de implementar exames para comprovação de conhecimentos dos professores, o ministro Fernando Haddad institui a prova pela Portaria Normativa, em 21 de maio de 2010. Após o questionamento da concepção da prova, foram convocadas entidades sindicais, de gestores e pesquisadores para participarem das discussões governamentais. Foram debatidas questões referentes à concepção da prova como avaliação do Curso de Pedagogia; a não afirmação explícita do concurso público para o ingresso na carreira; a duplicação da prova com a avaliação de desempenho; a autonomia dos estados e municípios na elaboração de provas de concurso. Quanto às questões das provas, foram contratados especialistas, por edital, para sua formulação. Em 2 de março de 2011, a Portaria Normativa n. 3 foi assinada, instituindo a Prova Nacional de Concurso para o Ingresso na 
Carreira Docente. Seus objetivos são: I - subsidiar os estados, o Distrito Federal e os municípios na realização de concursos públicos para a admissão de docentes para a educação básica; II - conferir parâmetros para autoavaliação dos participantes da Prova, com vistas à continuidade de sua formação e à inserção no trabalho docente; III - fornecer subsídios qualitativos que possam ser incorporados à formulação e à avaliação de políticas públicas de formação inicial e continuada de docentes.

Em 2011, foi instituído o Comitê de Governança da Prova, de caráter consultivo, composto por representantes do Consed (2); Undime (2); CNTE (2); das entidades de estudos e pesquisas em educação (1); Forundir (1) e seus respectivos suplentes.

A instituição do Concurso de Provas para o Ingresso na Carreira Docente é uma proposta que tem sido reconhecida como incentivo a uma formação centrada na prática escolar. Tem, também, o mérito de valorização do magistério com sólida formação teórico-prática, induzida pela expectativa de participação na prova para o ingresso na carreira.

A instituição do Concurso de Provas para o Ingresso na Carreira Docente traz ainda algumas indagações. A pergunta de Shiroma e Schneider (2011) é instigante: Por que tanta prioridade às políticas de avaliação de docentes? Avaliação pautada na meritocracia, na competição entre pares, na responsabilização pelos resultados e na flexibilização salarial não fazem parte de uma intenção de incutir na educação brasileira uma cultura de avaliação preponderante no setor empresarial? Não representa também o estímulo à competição de indivíduos que se autoavaliam e se inserem numa perspectiva de mobilidade em todo o território nacional?

\section{Ingresso de professores nas redes públicas em estados pesquisados}

Na pesquisa foram analisados (de 2010 a 2013) os ordenamentos legais referentes aos processos de ingresso dos profissionais do magistério da educação básica pública, em 12 estados da Federação (Paraná, Santa Catarina, Rio Grande do Sul, São Paulo, Minas Gerais, Mato Grosso, Mato Grosso do Sul, Piauí, Rio Grande do Norte, Paraíba, Pará e Roraima). O objetivo da pesquisa é analisar a efetivação ou não do dispositivo constitucional que prevê o ingresso exclusivo por concurso público de provas e títulos (inciso V do artigo 206 da Constituição Federal/1988).

O que se constata na análise dos estados pesquisados, sobre o ingresso do professor no setor público, é a afirmação da exclusividade do ingresso por concurso público, seguida por uma inclusão, na legislação, de incisos que permitem manter uma rede de professores temporários. Isto ocorre em todos os estados em que foi realizada a pesquisa. Esta regularidade nos resultados nos leva a inferir que há legitimação da contratação de professores temporários, o que pode gerar efeitos 
destrutivos para a carreira docente pública. Observou-se que nos estados e capitais pesquisados há grande número de contratos de professores temporários. A exceção foi constatada em Belo Horizonte e Curitiba, que não possuem professores com contratos temporários.

Nas regiões Norte e Nordeste, a legislação pesquisada mostra que, no sistema público da Paraíba, a estrutura de pessoal docente da rede estadual envolve o Quadro dos Efetivos (docentes concursados, com formação pedagógica); o Quadro Extraordinário (docentes que ingressaram na função, sem concurso público, pelo menos cinco anos antes da vigência da Constituição Federal de 1988); o Quadro Especial (contratados sem prévio concurso após a data da edição do plano de carreira, em 2003, e não fazem jus aos mesmos direitos dos pertencentes aos dois anteriores) e Quadro Complementar. O contrato de professores sem concurso público prévio é autorizado pela Lei n. 7.419, de 15 de outubro de 2003 (Plano de Cargos e Carreiras e Remuneração dos Profissionais da Educação do Estado da Paraíba - PCCR-PB).

No Rio Grande do Norte, está previsto no Plano de Carreira, Estatuto e Plano de Cargos, Carreira e Remuneração do Magistério Público Estadual da Educação Básica e da Educação Profissional (Lei Complementar n. 322/06) que o ingresso depende de concurso público. Contudo, o contrato temporário está disposto na Lei Complementar n. 322/2006, dando sequência a normas anteriores. A Portaria de 3 de junho de 2009 autoriza, também, alunos estagiários a assumirem atividades docentes, como estabelece o artigo 81:

Na falta de professores(as)/as habilitados, em razão de afastamentos decorrentes de licença médica ou vacância de cargos de seus titulares, as atividades docentes poderão ser exercidas por alunos de Instituições de Ensino Superior, devidamente reconhecidas pelo Ministério da Educação, admitidos como alunos estagiários, desde que estejam cursando a partir do $3^{\underline{0}}$ período.

A jornada dos estagiários é de seis horas diárias ou trinta horas por semana. Em 2007, o Ministério Público do Trabalho ajuizou Ação Civil Pública (ACP) para que o governo substitua todos os estagiários utilizados de forma irregular para substituir servidores concursados. Em 2010, o estado do Rio Grande do Norte firmou acordo extrajudicial com o Ministério Público para realizar concurso público para o preenchimento de 4 mil vagas de professores.

No estado do Piauí, afirma-se no Estatuto e no Plano de Cargos Carreira e Vencimento dos Trabalhadores em Educação Básica do Estado do Piauí que o ingresso na carreira se fará, exclusivamente, por concurso público de provas ou provas e títulos (Lei n. 71/06). O artigo 53 da Lei n. 71/06 legitima a substituição em caráter temporário e proíbe "a admissão, contratação, nomeação, designação e indicação de pessoas não habilitadas para o exercício de cargos ou funções de magistério". 
No Pará, a legislação dispõe que o ingresso se fará exclusivamente por concurso público de provas e títulos (Lei n. 5.351/1986). O Estatuto prevê a permanência no Quadro Suplementar de professores não habilitados:

Art. 10 - Quadro Suplementar será constituído dos cargos e funções de magistério cujos ocupantes não possuam qualificação prevista na legislação federal e exigida neste Estatuto.

Parágrafo Único - Somente será permitido o ingresso do servidor no Quadro Suplementar, quando a oferta de professores(as), legalmente habilitados, não atendem às necessidades do ensino.

Art. 11 - Os ocupantes de cargos e funções do Quadro Suplementar do Magistério terão acesso aos cargos do Quadro Permanente do Magistério, através de concurso público, salvo os casos previstos no artigo 58 deste Estatuto.

A contratação de professores temporários em detrimento de professores aprovados em concurso levou o Ministério Público a realizar o Termo de Ajustamento de Conduta com o governo do estado. O Sindicato dos Professores do Estado do Pará (Sintepp) afirma que havia mais de 6 mil professores com contratos temporários, em 2011.

Em Alagoas, o Termo de Ajustamento de Conduta (TAC) aprovado em dezembro de 2010, estabelece que, em João Pessoa, caberia, também, à prefeitura do município exonerar, até o final dezembro daquele ano, todos os temporários que ocupassem cargos que possuíssem aprovados aguardando nomeação. A contratação temporária passou a poder ser feita somente por 12 meses, sendo especificado o motivo da contratação; em caso de descumprimento, haveria multa diária por cada servidor temporário.

Em Roraima, o Plano de Carreira, Remuneração e Valorização do Magistério Público Estadual define o concurso público de provas e títulos como a forma de ingresso ao magistério. No artigo 42 da Lei n. 321/2001, dispõe sobre a contratação de professores temporários por processo seletivo simplificado.

Na região Sudeste, verifica-se que a duplicidade de ingresso não é recente em São Paulo. Está presente desde o Estatuto do Magistério Paulista (Lei Complementar n. 444, de 27 de dezembro de 1985) e coexistem duas formas de ingresso no magistério: concurso público e admissão. O concurso público dá direito a nomeação e admissão para a função-atividade que é realizada por concurso seletivo simplificado. A mesma lei determina que o preenchimento das funções-atividades da série de classes de docentes será efetuado mediante admissão para reger classes e/ou ministrar aula cujo número reduzido, especificidade ou transitoriedade não justifiquem o provimento de cargos. Mais de uma década após a elaboração do estatuto, o Plano de Carreira (Lei Complementar n. 836, 1997) retoma o conceito de função-atividade para justificar o contrato temporário. A jornada inicial é destinada aos novos integrantes da carreira, mas não para os temporários. 
Há, também, professores admitidos como eventuais convocados para substituírem ausências de professores, criando, deste modo, uma nova categoria, além dos efetivos e dos contratos temporários. Os eventuais não têm contrato temporário e sua remuneração refere-se às horas-aulas ministradas. As resoluções que dispõem sobre a atribuição anual de aulas definem que, encerrada a Etapa Complementar do processo de acesso às aulas, serão divulgadas vagas para admissão eventual, a serem atribuídas pelo diretor da unidade escolar (a Apeosp estima que em 2010 havia mais de 104 mil professores temporários na rede estadual). Dados da própria Secretaria Estadual de Educação (SEE/SP) apontam a existência de aproximadamente 37\% de professores temporários, em 2010, atuando na rede estadual de ensino, proporção que pode chegar a $44 \%$, se considerarmos, também, os professores admitidos na condição de eventuais.

Em Minas Gerais, o Plano de Carreiras dos Profissionais da Educação Básica do Estado de Minas Gerais (Lei n. 15 293/2004) define que o ingresso em cargo de carreira depende de aprovação em concurso público de provas ou de provas e títulos. Outras formas de ingresso são a admissão por função pública e a efetivação. A função pública foi instituída pela Lei n. 10.254/1990 para enquadrar os profissionais regidos pela CLT e é aplicada também aos professores designados (contratados). Em 2007, a Lei Complementar n. 100 estabeleceu Regime Próprio de Providência dos Servidores e, em decorrência, o governo estadual efetivou todos os servidores admitidos temporariamente, de dezembro de 1998 até 31 de dezembro de 2006 (o Sindicato dos Funcionários Públicos estima cerca de 100 mil servidores). A partir de 2008 a contratação de professores temporários continuou a vigorar e, em 2010, o Sindicato dos Trabalhadores da Educação estimou em 56 mil os contratos temporários.

O professor detentor de função pública (aquele que possui contrato temporário ou comissionado) é posicionado na carreira no nível e grau correspondentes à sua habilitação "apenas para fins de percepção do vencimento básico, mantida a identificação com a função pública", sem integrar a carreira do magistério público.

Na região Sul, é possível verificar que, no Paraná, segundo o Estatuto do Magistério Público do Estado do Paraná (Lei Complementar n. 7, de 22 de dezembro de 1976), o ingresso se fará mediante concurso público de provas e títulos. Este critério é reafirmado no Plano de Carreira do Professor da Rede Estadual de Educação Básica (Lei Complementar n. 103/2004), que estabelece o ingresso no Nível I, Classe 1, da Carreira, mediante concurso público de provas e títulos. A Lei do Plano de Carreira criou o Programa de Desenvolvimento Educacional, que certifica professores não habilitados e dá ao professor participante direito à promoção. O contrato temporário é mantido e podem se inscrever, no Cadastro de Contratações Temporárias, os candidatos que comprovem a escolaridade exigida. 
A contratação de pessoal por tempo determinado, para atender a necessidade temporária de excepcional interesse público, foi determinada em 2005 pela Lei Complementar n. 108/2005, que autoriza o concurso por processo simplificado: "O recrutamento do pessoal a ser contratado nos termos desta Lei será feito mediante processo seletivo simplificado sujeito a ampla divulgação, inclusive através do Diário Oficial do Estado, prescindindo de concurso público" (Lei Complementar n. 108/2005).

Em 2010, 36\% dos professores e pedagogos em atividade na rede estadual, segundo o Sindicato de Professores, eram contratados pelo regime especial de trabalho. Em Santa Catarina, o Estatuto do Magistério Público Estadual do Estado de Santa Catarina (Lei n. 6.844, de 29 de julho de 1986) estabelece a investidura em cargo público pelo concurso público. A Lei Complementar n. 1.139, de 28 de outubro de 1992, dispõe sobre Cargos e Carreiras do Magistério Público Estadual e autoriza "aulas excedentes", afirmando que os valores recebidos nestas aulas não se incorporam, em hipótese alguma, à remuneração percebida pelo servidor, exceto para proventos de aposentadoria, de acordo com a média dos três últimos anos. A Lei n. 8.391, de 13 de novembro de 1991, disciplina a admissão de pessoal em caráter temporário, permitida "no que exceder à capacidade dos servidores efetivos". A Secretaria da Educação completa o quadro da rede estadual com professores admitidos em caráter temporário (ACTs) e tem aberto inscrições de processo seletivo para contratos temporários (Edital n. 27/ SEC) em 2010, 2011 e 2012.

No Rio Grande do Sul, o Estatuto e Plano de Carreira do Magistério Público do Rio Grande do Sul (Lei n. 6.672, de 22 de abril de 1974) estabelece a aprovação prévia em concurso público. A Lei n. 10.576/95 autoriza contratações temporárias "para atender necessidade temporária de excepcional interesse público, a Administração Estadual poderá efetuar contratações de pessoal, por prazo determinado".

No Mato Grosso Sul, o Estatuto dos Funcionários Públicos (Lei n. 1.102, de 10 de outubro de 1990) considera as substituições de professores como de necessidade temporária e emergencial, realizadas por processo seletivo simplificado.

O Estatuto dos Profissionais da Educação Básica do Estado de Mato Grosso do Sul (Lei n. 5.193, de 1ํ de fevereiro de 2000) institui o concurso público de provas e títulos. Entretanto, é autorizada a Suplência, que é o exercício em caráter temporário da função docente, e ocorrerá: I - por aulas complementares; II - por convocação (art. 16). A convocação é atribuição da função de docente, em caráter temporário, a profissional de educação básica ou a candidato que possua habilitação para atuar como docente da educação básica (redação dada pela Lei Complementar n. 115, de 2005). A convocação fica limitada a cada período, não podendo ter início durante as férias, salvo necessidade imperiosa de reposição de aulas, e o valor da hora-aula é 
igual ao do vencimento na classe A, no nível correspondente à habilitação do convocado. Define que "não incidirá contribuição para o regime de previdência social do Estado sobre a remuneração percebida pelo professor ocupante de cargo efetivo no exercício de aulas complementares"' (LC n.115/2005).

A Lei n. 3.519, de 15 de maio de 2008, instituiu o subsídio como forma de remuneração dos servidores, alterando o Plano de Carreira, embora tenha mantido a legislação anterior. O Sindicato dos Professores do Mato Grosso do Sul estima que 49\% dos professores tinham contrato temporário, em 2012.

No estado do Mato Grosso, o Plano de Carreira dos Profissionais da Educação Básica de Mato Grosso (Lei Complementar n. 50, de $1^{\circ}$ de outubro de 1998) exige concurso público de provas ou de provas e títulos. Quanto ao contrato provisório, a Lei define que, "Em caso de necessidade comprovada, [...] poderão ser admitidos Profissionais da Educação Básica mediante contrato temporário".

Portanto, a primeira conclusão é que, na maioria das redes de ensino investigadas, existe a estratégia da contratação de professores em caráter temporário, para suprir carências, em lugar de concursos públicos, criando, assim, uma subcategoria de professores no interior dos sistemas de ensino e das unidades escolares.

Para que seja alcançada a Meta 18.1 do Plano Nacional de Educação, que propõe: "Estruturar os sistemas de ensino, buscando atingir, em seu quadro de profissionais do magistério, noventa por cento de servidores nomeados em cargos de provimento em efetivo exercício na rede pública de educação básica", seria necessária a institucionalização de uma Política Nacional de Formação e Valorização dos Profissionais da Educação, garantindo o cumprimento da Constituição Federal de 1988, da Lei n. 9.394/96 (LDBEN) e das legislações conexas com direito à carreira, salários dignos e satisfatórias condições de trabalho.

Para esta institucionalização, o Plano Nacional de Educação deverá garantir, sem subterfúgios, a ampliação dos recursos. As desigualdades da educação brasileira não se restringem à qualificação dos professores: a ampliação dos recursos destinados à educação e a participação da União em sua redistribuição são fundamentais para a construção de mais justiça na educação.

\section{Referências}

ABICALIL, C.A. Piso salarial: constitucional, legítimo, fundamental. Retratos da Escola, Brasília, DF, v. 2, n. 2-3, p. 67-80, jan./dez. 2008. Disponível em: <http//www. esforce.org.br>

AVELAR, H. A. História administrativa e econômica do Brasil. 5 ed. Rio de Janeiro: MEC, 1983. 
APEOSP. Notícias professores(as)/as temporários. Disponível em: <http://www.apeoesp. org.br/noticias/noticias>.

BALZANO, S. Estudo dos planos de carreira e remuneração do magistério da educação básica dos estados brasileiros. Consed RH - GT Valorização do Magistério, jul. 2005.

BRASIL. Projeto de Lei n. 8.035/2010. Cria o Plano Nacional de Educação (PNE). Brasília, DF: MEC, 2010.

BRASIL. Lei n. 9.394 de 20 de dezembro de 1996. Estabelece as diretrizes e bases da educação nacional. Brasília, DF: MEC, 1988.

BRASIL. Constituição da República Federativa do Brasil. Brasília, DF: Senado Federal, 1988.

BRASIL. Lei n. 4.024, de 20 de dezembro de 1961. Fixa as Diretrizes e Bases da Educação. Brasília, DF: MEC, 1961.

FERREIRA, C. M. Crise e reforma do Estado: uma questão de cidadania e valorização do servidor. Revista do Serviço Público, Brasília, DF, v. 120, n. 3, p. 5-33, set./dez. 1996.

FERREIRA, A.G; VECHIA, A.V. Instruir elites em meados do século XIX: o Liceu de Coimbra e o Imperial Colégio de Pedro II. Congresso CBHE, 2010. Disponível em: <ehttp://sbhe.org. br/novo/congressos/cbhe3/Documentos/Individ/Eixo2/057.Pdf>

MATO GROSSO (Estado). Lei Complementar n. 50, de 1ํ de outubro de 1998. Dispõe sobre o Plano de Carreira dos Profissionais da Educação Básica de Mato Grosso.

MATO GROSSO DO SUL (Estado). Lei Complementar n. 115, de 2005. Dispõe sobre o Estatuto dos Profissionais da Educação Básica do Estado de Mato Grosso do Sul.

MATO GROSSO DO SUL (Estado). Lei n. 1.102, de 10 de outubro de 1990. Dispõe sobre o Estatuto dos Funcionários Públicos Civis do Poder Executivo, das Autarquias e das Fundações Públicas do Estado de Mato Grosso do Sul.

MEDEIROS, P.H.R. Do modelo racional legal ao paradigma pós-burocrático: reflexões sobre a burocracia estatal. Organizações $\mathcal{E}$ Sociedade, Salvador, v. 13, n. 37, abr./jun. 2006.

MINAS GERAIS (Estado). Lei Complementar n. 100, de 5 de novembro de 2007. Institui a Unidade de Gestão Previdenciária Integrada - Ugeprevi - do Regime Próprio de Previdência dos Servidores Públicos do Estado de Minas Gerais e do Regime Próprio de Previdência dos Militares do Estado de Minas Gerais e o Conselho Estadual de Previdência - Ceprev - altera a Lei Complementar n. 64, de 25 de março de 2002 e dá outras providências. 
MINAS GERAIS (Estado). Lei n. 10.254/1990, de 20 de julho de 1990. Institui o regime jurídico único do servidor público civil do Estado de Minas Gerais e dá outras providências.

MINAS GERAIS (Estado). Lei n. 15.293, de 5 de agosto de 2004. Dispõe sobre o Plano de Carreiras dos Profissionais da Educação Básica do Estado de Minas Gerais.

MINISTÉRIO PÚBLICO DO TRABALHO DO ESTADO DA PARAÍBA. Ação Civil Pública. Disponível em: <www.paraiba.com.br/2011/11/08/22070>

NÓVOA, A. Para o estudo sócio-histórico da gênese e desenvolvimento da profissão docente. Teoria E Educação, Porto Alegre, n. 4, p. 109-139, 1991.

PARÁ (Estado). Lei n. 5.351/1986. Dispõe sobre o Estatuto do Magistério Público Estadual do Pará. Disponível em: <http://www.mp.pa.gov.br/index.php?action=Menu. interna\&id $=1606 \&$ class $=N>$.

PARÁ (Estado). Lei n. 5.810/2004. Dispõe sobre o Estatuto do Magistério Público Estadual do Pará.

PARÁ (Estado). Lei n. 321, de 31 de dezembro de 2001. Dispõe sobre o Plano de Carreira, Remuneração e Valorização do Magistério Público Estadual e dá outras providências.

PARAÍBA (Estado). Lei n. 7.419, de 15 de outubro de 2003. Dispõe sobre o Plano de Cargos e Carreiras e Remuneração para o Grupo Ocupacional do Magistério do Estado da Paraíba e dá outras providências.

PARANÁ (Estado). Lei Complementar n. 7, de 22 de dezembro de 1976. Dispõe sobre o Estatuto do Magistério Público do Estado do Paraná.

PIAUÍ (Estado). Lei Complementar n. 71, de 26 de julho de 2006. Dispõe sobre o Estatuto e o Plano de Cargos e Carreira e Vencimento dos Trabalhadores em Educação Básica do Estado do Piauí e dá outras providências.

RIO GRANDE DO SUL (Estado). Lei n. 10.576, de 14 de novembro de 1995. Dispõe sobre a gestão democrática do ensino público e dá outras providências.

RIO GRANDE DO SUL (Estado). Decreto n. 45.754, de 20 de abril de 2008. Institui o Cadastro de Contratações Temporárias.

RIO GRANDE DO SUL (Estado). Lei n. 6 672, de 22 de abril de 1974. Dispõe sobre o Estatuto e Plano de Carreira do Magistério Público do Rio Grande do Sul.

RORAIMA (Estado). Lei n. 321, de 31 de dezembro de 2001. Dispõe sobre o Plano de Carreira, Remuneração e Valorização do Magistério Público do Estado de Roraima e dá outras providências. 
RORAIMA (Estado). Lei n. 609, de 6 de agosto de 2007. Dispõe sobre a carreira do Magistério Público do Estado de Roraima e dá outras providências.

SANTA CATARINA (Estado). Lei Complementar n. 1.139, de 28 de outubro de 1992. Dispõe sobre Cargos e Carreiras do Magistério Público Estadual.

SANTA CATARINA (Estado). Lei n. 6.844, de 29 de julho de 1986. Dispõe sobre o Estatuto do Magistério Público Estadual do Estado de Santa Catarina.

SANTA CATARINA (Estado). Lei n. 8.391, de 13 de novembro de 1991. Disciplina a admissão de pessoal em caráter temporário sob regime administrativo especial, no âmbito do Magistério Público Estadual e dá outras providências.

SÃO PAULO (Estado). Lei Complementar n. 444, de 27 de dezembro de 1985. Dispõe sobre Estatuto do Magistério Paulista e dá providências correlatas.

SÃO PAULO (Estado). Lei Complementar n. 836, de 1997. Institui o Plano de Carreira, Vencimentos e Salários para os integrantes do Quadro do Magistério da Secretaria da Educação e dá outras providências correlatas.

SHIROMA, E.O.; SCHNEIDER, M.C. Professores em exame: reflexões sobre políticas de avaliação docente. Práxis Educativa, Ponta Grossa, v. 6, n. 1, p. 31-44 , jan.-jun. 2011. Disponível em: <http://www.periodicos.uepg.br>.

SUPIOT, A. A crise do espírito de serviço público. Revista da Associação de Docentes da UFRGS, Porto Alegre, v. 5, n. 7, p. 17- 25, jul. 1995.

Recebido em 19 de julho de 2013.

Aprovado em 25 de novembro de 2013. 
